\title{
CONCEPT ANALYSIS
}

\section{A concept analysis of undergraduate nursing students speaking up for patient safety in the patient care environment}

\author{
Anthea Fagan, Vicki Parker \& Debra Jackson
}

Accepted for publication 16 May 2016

Correspondence to A. Fagan:

e-mail: afagan2@une.edu.au

Anthea Fagan BN MN RN

Lecturer in Nursing

School of Health, University of New

England, Armidale, NSW, Australia

Vicki Parker PhD RN

Professor of Nursing

School of Health, University of New

England, Armidale, NSW, Australia and the Hunter New England Area Health Service,

Valentine, NSW, Australia

Debra Jackson PhD RN

Professor of Nursing

School of Health, University of New

England, Armidale, NSW, Australia and

Oxford Brookes University and Oxford

University Hospitals, UK
FAGAN A., PARKER V. \& JACKSON D. (2016) A concept analysis of undergraduate nursing students speaking up for patient safety in the patient care environment. Journal of Advanced Nursing 00(0), 000-000. doi: 10.1111/jan.13028

\begin{abstract}
Aim. An analysis of the concept of nursing students speaking up for patient safety in the workplace.

Background. 'Speaking up' is assertive communication in clinical situations that requires action through questions or statements of opinion or information with appropriate persistence and is linked to patient safety. Previously, the concept of speaking up has focused on the registered or experienced practitioners, there is minimal discussion relating to student nurses. Analysis of the elements of students speaking up will identify the key elements that will give understanding to their position and experiences.
\end{abstract}

Design. A concept analysis.

Data. Literature included publications between 1970-2015 from, MEDLINE, CINHAL, PUBMED and SCOPUS. Search terms included patient safety AND speaking up; AND pre-registration/undergraduate nursing students, patient advocate, error reporting, organizational silence, whistleblowing and clinical placement/practicum.

Methods. The Walker and Avant concept analysis model was modified and used to examine the literature.

Results. Nursing students speaking up behaviour is influenced by individual and contextual factors that differ from those influencing more experienced colleagues. Motivators and barriers to voicing concerns include moral and ethical beliefs, willingness and confidence to speak up in the workplace. Students' subordinate and often vulnerable position creates additional tensions and challenges that impact their decisions and actions.

Conclusion. This concept analysis provides a clear definition of 'speaking up' in relation to nursing students. The analysis will facilitate understanding and operationalization of the concept applied to learning and teaching, practice and research.

Keywords: clinical placement/practicum, error reporting, organizational silence, patient advocate, patient safety, pre-registration, speaking up, undergraduate nursing students, whistleblowing 


\section{Why is this research or review needed?}

- Recognition and disclosing of unsafe practice is essential to ensure patient safety, prevent errors and achieve optimal patient outcomes.

- The concept of speaking up has been described in relation to registered or experienced practitioners but not from the perspective of student nurses.

- Concept clarification is necessary to inform undergraduate education, practice and research that will improve culture and outcomes.

\section{What are the key findings?}

- Nursing student's role and position in the workplace differs from other health professionals in relation to speaking up and disclosing errors.

- Antecedents for nursing students to speak up and report errors include individual factors; students' clinical knowledge and safety knowledge; cultural and generational background; attitude, confidence and contextual factors; organisational structure; and supervision and support.

- There is evidence to suggest that nurses do not always speak up; for students to speak up they require sound clinical knowledge, commitment to patient safety, speaking up skills and confidence along with good supervision and support in the clinical environment.

How should the findings be used to influence policy/ practice/research/education?

- This concept analysis will provide direction and clarity and highlight the importance of addressing speaking up activities when evaluating student nurse curricula.

- The findings will inform research directed towards improving student practice in speaking up, that will flow on to cultural change.

- Managers and student supervisors will have awareness of the particular challenges experienced by students and thus, be better equipped to provide appropriate support to facilitate student nurses speaking up.

\section{Introduction}

Speaking up for patient safety is a concept that is becoming increasingly important in health care as patient's experiences become more complex and fragmented, resulting in greater potential for patient harm (Ion et al. 2015). The World Health Organization (WHO) reports there is a one in 300 chance of a patient being harmed during health care (WHO 2015). Health professionals' failure to communicate concerns has been shown to result in avoidable patient harm (Kohn 2000, Reason 2000, Garling 2008, Francis 2013). 'Speaking up' has been defined as assertive communication in clinical situations that requires (immediate) action through questions, statements of opinion or information with appropriate persistence aiming for resolution (Premeaux \& Bedeian 2003, Lyndon et al. 2012, Schwappach \& Gehring 2014). While there is a clear link between speaking up and patient safety (Francis 2013, Okuyama et al. 2014), there is a evidence to suggest that nurses do not always speak up (Moss \& Maxfield 2007, Henneman et al. 2010, Kolbe et al. 2012, Schwappach \& Gehring 2014). Researchers have explored the individual, social and organizational contexts that contribute to nurses not speaking up (Henriksen \& Dayton 2006, Mannion \& Davies 2015). The focus has been largely on Registered Nurses (RNs) attitudes and practices with very little attention to undergraduate nursing students. Understanding of the phenomenon of speaking up from a student nurse perspective is essential to help develop student's speaking up skills.

\section{Background}

Error reporting has been evident in the literature over the last 35 years. It has been described using various terms including whistleblowing, error disclosure, speaking up and patient advocacy (Ahern \& McDonald 2002, Attree 2007, Jackson et al. 2010, Peters et al. 2011, Rainer 2015). Others refer to the lack of reporting as organizational silence, a culture of silence or collusion that protects staff rather than patients (Garon 2012, Maxfield et al. 2011, Mannion \& Davies 2015).

Speaking up derives from the notion of 'human advocate' first described by Curtin (1979). Advocacy, with a focus on patient safety advocacy was later developed through models where a patient advocate was described as a counsellor, watchdog, representative and whistleblower (Gadow 1980, Konke 1982, Fowler 1989, Baldwin 2003). In the early 2000s, there was a fundamental shift in healthcare attitudes in relation to advocacy and accountability, nurses took a more autonomous role in their practice. This resulted in enabling them to voice concerns and advocate for patient safety (Ahern \& McDonald 2002).

The literature examining nurses' propensity to speak up and the consequences that result from speaking up, highlight the complex and difficult nature of exposing errors made by colleagues (Kolbe et al. 2012, Schwappach \& Gehring 2014). There are numerous accounts in the literature that nurses fear reprisal, being ostracised, dismissed and silenced as a result of reporting errors (Jackson et al. 
2010, Peters et al. 2011, Barnsteiner \& Disch 2012). The decision to speak up may be viewed as courageous or dangerous, placing the interests and welfare of patients above those of self and colleagues. However, codes and standards of practice clearly indicate the responsibility to speak up is an expectation of health professionals (Nursing and Midwifery Board of Australia [NMBA] 2008a,b, WHO 2009, American Nurses Association 2015). This confusing backdrop creates uncertainty for students who may find it difficult to make sense of their role and position in relation to speaking up.

Undergraduate nursing students on clinical practicum care directly for the patient and may encounter the need to advocate for patient safety. However, they are in a subservient position requiring constant supervision by a nurse with more authority (Melincavage 2011, Suresh et al. 2012, Walker et al. 2014, Ion et al. 2015). Students are in a difficult situation when speaking up against more senior nurses, because they fear it may impact how they are treated and their ability to successfully complete placements (Melincavage 2011 Ion et al. 2015). Internationally, nursing students are required to practice according to the regulatory codes that guide behaviours and responsibilities in the same way required of RNs. In the instance of witnessing unlawful conduct of co-workers, they have both the responsibility and obligation to report and prevent harm (NMBA 2008a, b, Department of Health/Patient Safety 2012, Nursing Council of New Zealand 2012, American Nurses Association 2015).

Studies conducted in Europe (Kolbe et al. 2012), Hong Kong (Law \& Chan 2015), the Middle East (Mansbach et al. 2014), Europe (Schwappach \& Gehring 2014), USA (Garon 2012, Mariani et al. 2015, Rainer 2015) and UK (Andrew \& Mansour 2014, Ion et al. 2015) have taken different approaches aiming to understand speaking up across various settings. Research focusing on nursing students' responses to error or speaking up include; reporting professional misconduct (Mansbach et al. 2014), willingness to report misconduct (Mansbach et al. 2014, Ion et al. 2015), education aimed at increasing speaking up confidence (Kent et al. 2015) and students responses to errors in hypothetical cases (Andrew \& Mansour 2014). What has not been examined in the literature is the way speaking up for students differ from that of their RN colleagues. In particular, how being a learner and new to the culture of nursing creates a different set of circumstances that students need to negotiate to speak up. Hence, there is a need for clarification of the concept as it applies to students.

A modified Walker and Avant (2010) approach was used to develop the concept analysis of nursing students speaking up in the workplace. It will define 'speaking up' and examine the characteristics, antecedents, consequences and implications for practice. Clarification of the concept will increase understanding of the nature and circumstances of speaking up from a student's perspective and aims to improve practice in this area and thus, contribute to patient safety.

\section{Data sources}

The literature search was conducted using the following search terms; patient safety AND speaking up and preregistration/undergraduate nursing students, patient advocate, error reporting, organizational silence, whistleblowing and clinical placement/practicum. All relevant sources were examined with the focus being limited to nurses speaking up, reporting and disclosure of errors and patient safety. Due to the limited literature on students specifically, the search inclusion criteria was broadened to include all nurses. The search was limited to English language and articles published between 1970-2015 as seminal research relating to advocacy in nursing dates from the late 1970s. Exclusion criteria included; speaking up against violence, patients and relatives speaking up, disease related or medical conditions affecting voice and speech, the medical profession and literature on evaluating patient safety curriculum. The method for the concept analysis as described by Walker and Avant (2010) was applied through the following six steps (1) define the concept of students speaking up; (2) determine the aim of the analysis; (3) build a theoretical basis for students speaking up; (4) identify all uses of the concept; (5) determine and discuss the critical attributes and (6) identify antecedents and consequences. Table 1 outlines the key terms presented in the concept analysis.

\section{Results}

Originally 566 articles were retrieved; CINHAL (52), MEDLINE (299), PUBMED (72) and SCOPUS (123). After applying exclusion criteria and deletion of duplicates, 19 articles were deemed relevant. Examination of the reference lists and forward citation through GOOGLE Scholar of relevant articles resulted in 12 further articles. Thirty-one articles were used to conduct the concept analysis (Table 2).

\section{Defining attributes of speaking up}

Defining attributes are characteristics that appear repeatedly in the literature and are present every time the concept 
occurs (Walker \& Avant 2005). 'Speaking up' has been described as approaching or questioning clinical practice, decisions or actions that may compromise patient safety (Kent et al. 2015). Sayre et al. (2012) define 'speaking up' as the nurse using their voice to make others aware of information that might make a change ensuring the patient has a safe outcome. More specifically, 'speaking up' is defined as seeking clarification or explicitly challenging or correcting task-relevant decisions or procedures (Kolbe et al. 2012). Whistleblowing, on the other hand, is viewed as an action required when patients safety or rights are in danger (Mansbach et al. 2013). Whistleblowing has some differences to the concept of speaking up. Whistleblowing may involve incident reporting being extended beyond the organization to the media or to governing bodies (Firtko \& Jackson 2005). Furthermore, whistleblowing has been framed as a process where a disclosure, of what is believed

Table 1 Defining terms (Walker and Avant 2010).

Defining attributes are similar to signs and symptoms, are critical characteristics that help to differentiate one concept from another related concept and clarify its meaning.

Antecedents are the events or attributes that must arise prior to a concept's occurrence.

Consequences are those events or incidents that can occur as a result of the occurrence of a concept. to be illegal, immoral or illegitimate practice occurs to persons or bodies who can make a change (Jackson et al. 2014). There are similarities to the understandings of speaking up in the immediate sense, in that there is the aim to prevent harm by voicing concerns and advocating for the patient. The motivators to students speaking up must be considered to correlate with the outcome; preventing harm through error recovery, maintaining and improving patient safety (Ion et al. 2015). The defining attributes of nursing students speaking up for patient safety are described in Table 2 and discussed in more detail below. These defining attributes include: the student role as the patient advocate, the student's use of voice, silence and the reception of the message, or being heard, together with a sense of agency and confidence in the workplace.

\section{Patient advocacy role}

Advocacy as a key aspect of the speaking up concept (Ahern \& McDonald 2002, Rainer 2015). Advocacy has been defined as an intervention 'to help specific consumers obtain services and rights that would (likely) not otherwise be received and that would advance their personal wellbeing' (Jansson 2011, p. 3). Interceding is advocacy in action, when the nurse acts as a go-between, or arbitrator between patients, their families, statistically significant others and healthcare providers (Baldwin 2003). Advocacy,

Table 2 Themes related to speaking; defining attributes/antecedents and consequences.

\begin{tabular}{|c|c|}
\hline Articles & Defining attributes \\
\hline Ahern \& McDonald (2002), Baldwin (2003), Garon (2012), Jansson 2011, Rainer 2015 & Advocacy \\
\hline $\begin{array}{l}\text { Jackson et al. (2011), Kent et al. (2015), Levett-Jones \& Lathlean (2009), Melincavage } \\
\text { (2011), Myall et al. (2008) }\end{array}$ & Agency \\
\hline Jackson et al. (2011), Kent et al. (2015), Melincavage (2011), Reader (2015) & Disempowered \\
\hline Garon (2012), Mannion \& Davies (2015), Maxfield et al. $(2005,2011)$, Morrison (2011) & $\begin{array}{l}\text { Cultures of silence } \\
\text { Cultures of voice } \\
\text { Antecedents }\end{array}$ \\
\hline Bellefontaine (2009), Ion et al. (2015), Kent et al. (2015), Tella et al. (2015) & Clinical and safety knowledge \\
\hline Garon (2012), Hendricks \& Cope (2013), Rainer (2015), Xu et al. (2005) & $\begin{array}{l}\text { Cultural and generational } \\
\text { background }\end{array}$ \\
\hline $\begin{array}{l}\text { Ahern \& McDonald (2002), Andrew \& Mansour (2014), Attree (2007), Barnsteiner \& } \\
\text { Disch (2012), Mansbach et al. (2013), Melincavage (2011), Walker et al. (2014) }\end{array}$ & Attitude and confidence \\
\hline $\begin{array}{l}\text { Dendle et al. (2013), Ion et al. (2015), Levett-Jones \& Lathlean (2009), } \\
\text { Schwappach \& Gehring (2014) }\end{array}$ & $\begin{array}{l}\text { Professional position in practice } \\
\text { Personal culture }\end{array}$ \\
\hline $\begin{array}{l}\text { Barnsteiner \& Disch (2012), Garon (2012), Henriksen \& Dayton (2006), Johnson \& } \\
\text { Kimsey (2012), NHS Staff Survey (2012) }\end{array}$ & Organizational Structure/ \\
\hline $\begin{array}{l}\text { Dolansky et al. (2013), Levett-Jones \& Lathlean (2009), Melincavage (2011), } \\
\text { Suresh et al. (2012), Reader (2015) }\end{array}$ & Supervision and support \\
\hline $\begin{array}{l}\text { Bellefontaine (2009), Gallagher (2011), Ion et al. (2015), Levett-Jones \& } \\
\text { Lathlean (2009), Myall et al. (2008) }\end{array}$ & $\begin{array}{l}\text { Consequences of speaking up } \\
\text { Negative - reprisal }\end{array}$ \\
\hline Kolbe et al. (2012) & Positive - acceptance \\
\hline
\end{tabular}


as a central concept provides an underlying theory on which the action of speaking up rests (Rainer 2015). Advocacy and acting as a mediator between patients, families and healthcare providers are essential features of speaking up (Baldwin 2003). Effective advocacy occurs when nurses, including students, successfully communicate and voice their fears about particular actions to preserve patient safety (Garon 2012). Therefore, exploring the domains of voice and silence in relation to students helps to understand the actual action of speaking up conveying a message and being heard (Garon 2012, Law \& Chan 2015).

\section{Voice, silence and being heard}

The notion of 'voice' brings together aspects such as knowledge, professional position, experience and personality (Morrison 2011, Mannion \& Davies 2015). In addition, voice comprises the realms of verbal expression such as conveying a message from a sender to a receiver. Morrison's (2011) empirical research on employee voice correlates voice with behaviour. First, discretionary voice involves the choice to engage in voice or not. Second, voice is directed towards improvement and is positive in its intent, therefore, is constructive rather than merely complaining or venting. Voice can be classified as challenging, intending to change the status quo or promotive and valuable in its resolve (Garon 2012). Analysis of the concept of voice has resulted in an integrated understanding of voice as being discretionary communication of ideas, suggestions, concerns or opinions about work-related issues intending to improve organization or unit functioning (Morrison 2011, p. 375). Student nurses' perception of themselves as inferior and accountable to an individual in a supervisory role will influence their voice behaviour (Melincavage 2011).

Silence that is not voicing concerns is also a recognized behaviour that may impact patient safety. There are seven ways silence is manifested in practice (Maxfield et al. 2005) as seen in Table 3. Of these, particular relevance to students includes; mistakes or incompetence relating to lack of knowledge (Bellefontaine 2009) and lack of teamwork as students often feel unsupported in the workplace (Walker et al. 2014). Nursing students' use of voice is an active response, which correlates with individual factors such as powerlessness and organizational influences such as a safety culture (Melincavage 2011). There is evidence that suggests that a greater number of nurses than previously are expressing their concerns relating to safety (Maxfield et al. 2011). There is also evidence that students engage in acts of individual and collective agency in the clinical setting in spite of a range of contextual factors that might inhibit speaking up (Jackson et al. 2011).
Table 3 Seven crucial conversations in health care (Maxfield et al. 2005).

1 Broken rules - nurses and other clinical-care providers see some number of their co-workers taking shortcuts that could be dangerous to patients.

2 Mistakes - nurses observing poor clinical judgment when making assessments, doing triage, diagnosing, suggesting treatment, or getting help

3 Lack of support - Nurses experience colleagues who are reluctant to help, impatient or refuse to answer their questions peers.

4 Incompetence - clinical-care providers have concerns about the competency of some nurse or other clinical-care provider they work with

5 Poor Teamwork - nurses and other clinical-care providers have one or more teammate who gossips or is part of a clique that divides the team.

6 Disrespect - clinical-care providers work with some who are condescending, insulting or rude

7 Micromanagement - clinical-care providers work with some number of people who abuse their authority - pull rank, bully, threaten or force their point of view on them

A key characteristic of communication and speaking up is the delivery of the message and how it is perceived and received. Furthermore, emotion and tone used when voicing concerns influence the reception of the message (Garon 2012). Also, too much emotion or difficulty in searching for appropriate tone influences the perception and reception of the message being communicated (Garon 2012). Nursing students, who have emotional resilience and sense of agency overcome the fear of retribution, uncertainty and lack of confidence, resist organizational influences and use their voice in the workplace (Jackson et al. 2011).

\section{Sense of agency}

Nursing students present a sense of agency that differs from the RN (Melincavage 2011, Suresh et al. 2012, Walker et al. 2014). Students' sense of agency and self-determination while determining constraints of social structure in the workplace is also critical to enabling them to act independently and speak up (Levett-Jones \& Bourgeois 2014). Their perception of personal identity is dependent on the support they receive, positive role modelling and the sense of inclusiveness or acceptance (Walker et al. 2014). However, at times there is a sense of being inferior, ignored, threatened, lacking in experience, not belonging and uncertain of their ability to practice (Levett-Jones \& Lathlean 2008, Jackson et al. 2011, Melincavage 2011).

Personal accountability, self-identity and personal security are important factors impacting students' ability to advocate through speaking up (Rainer 2015). Their actions and role in safeguarding the patient from harm are 
influenced by certain elements including; willingness to engage in potentially compromising situations, engaging in responsibility and views on the consequences of speaking up (Mansbach et al. 2013, Andrew \& Mansour 2014). In response to their position, nursing students' willingness to express concerns correlates with their awareness of powerlessness and doubtfulness of their knowledge, thereby reducing their sense of agency leading to active silence (Barnsteiner \& Disch 2012). In this way, courage may be seen as a necessary attribute of speaking up. Moral courage involves activating intellectual virtue through professional responses that may inspire fear of the consequences, speaking up and challenging practice (Gallagher 2011).

\section{Antecedents and consequences}

Antecedents are the factors that can be identified as essential precursors to students' speaking up (Walker and Avant 2005). Factors that impact students speaking up behaviours reported in the literature include a sense of belonging (Levett-Jones \& Lathlean 2008), anxiety (Melincavage 2011) excessive workloads, difficult working relationships (Suresh et al. 2012), role and position in the healthcare team (Walker et al. 2014) and fear of retribution or failing their placement (Bellefontaine 2009, Ion et al. 2015). Factors can be categorised into individual or contextual influences. An adaptation of Morrisons' (2011) model of employee voice presented in Figure 1 illustrates characteristics, antecedents and consequences of nursing students speaking up in the workplace.

\section{Individual antecedents}

\section{Student knowledge}

Knowledge about acceptable and non-acceptable practice gives students the ability to recognize and respond to potentially harmful practice. Students sometimes feel they are not well prepared to deal with an event that requires them to

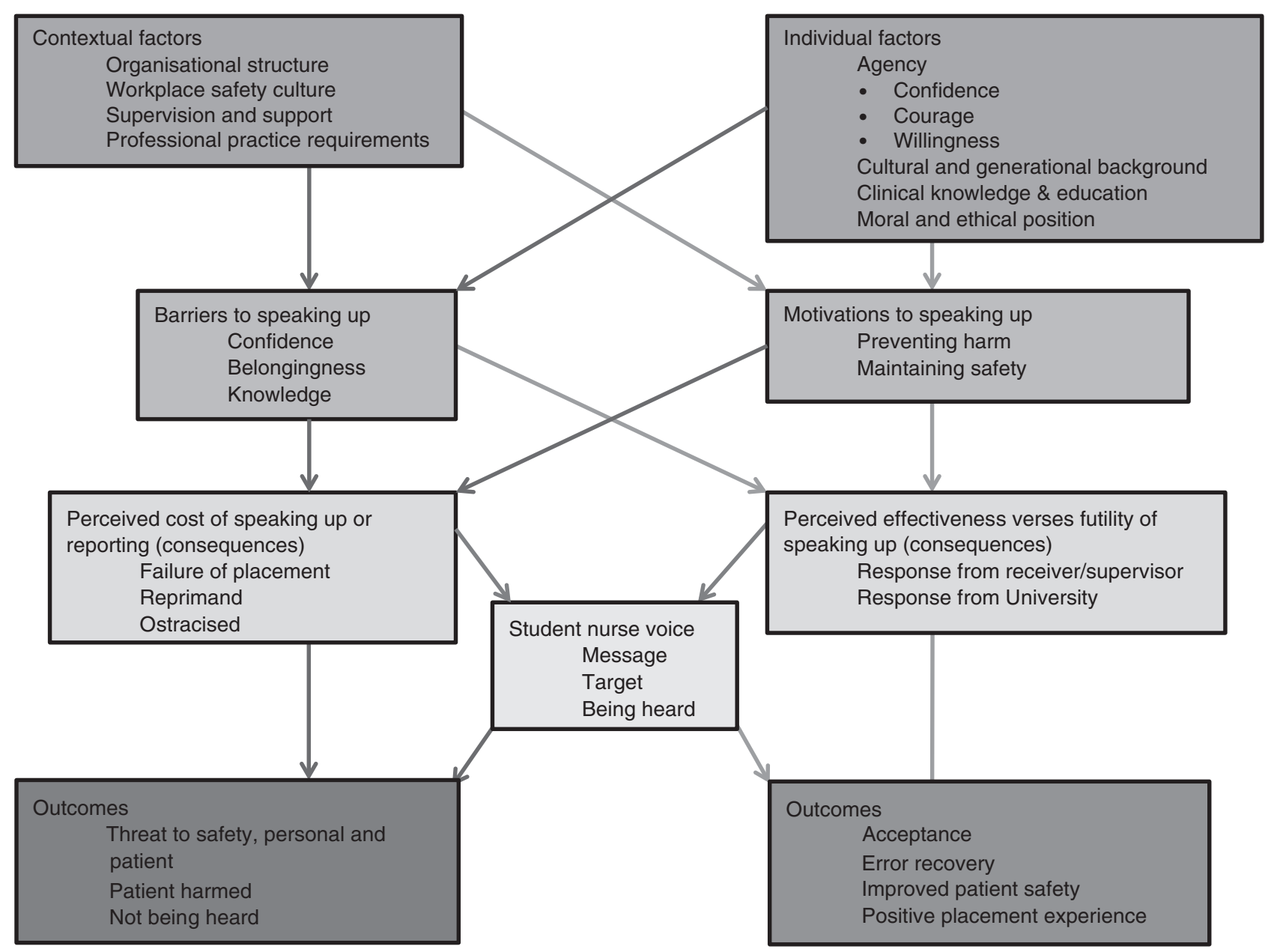

Figure 1 Adaptation of Morrison (2011) employee voice behaviour model for undergraduate nursing students. 
voice concerns and prevent patient harm (Ion et al. 2015). Knowledge base is a prerequisite to speaking up, knowing and understanding ethics and principles of safe practice. Conversely, lack of knowledge creates a barrier to speaking up (Bellefontaine 2009). A disconnection has been identified between theory and clinical practice in relation to safety (Tella et al. 2015). Kent et al. (2015) identified students reported increased confidence to voice concerns having participated in a speaking up programme. Specifically, students introduced to effective speaking up phrases such as 'I am concerned...' or 'I feel uncomfortable...' resulted in a statistically significant increase in students' assurance in speaking up. Furthermore, students required clarification of the processes involved of how their university will respond to students who report (Ion et al. 2015).

\section{Cultural and generational factors}

Characteristics such as ethnicity and age have been shown to influence propensity to speak up. Some authors argue that cultural backgrounds may affect the likelihood to speak up to persons of authority or to question to uphold an appearance or to respect persons of authority (Xu et al. 2005). Similarly, nurses with diverse cultural origins may be required transcend cultural norms of non-challenging acceptance of circumstances to speak up (Garon 2012). Furthermore, language barriers and lacking in understanding of sociocultural knowledge can create difficulties to speak up (Mannion \& Davies 2015). Generational characteristics may either impede or enhance speaking up and variations across generations are reported to exist concerning; respect for authority (Hendricks \& Cope 2013), ease in the workplace, levels of uncertainty and appreciation of and engagement in teamwork.

\section{Attitude and confidence}

In spite of reported generational influences, research findings suggest that students often feel powerless in their position, ignored by physicians and at times invisible, hence their sense of agency in the workspace is challenged (Melincavage 2011). Role and position differ between nursing students and RNs, which affects their engagement in speaking up for patient safety in the clinical environment (Jackson et al. 2011). Students may believe themselves to be subservient with negative views about the value of their contributions, poor self-concept and poor self-confidence (Mansbach et al. 2013, Andrew \& Mansour 2014, Walker et al. 2014). Education on speaking up has resulted in increased student confidence to advocate for patients safety (Kent et al. 2015). However, willingness, motivation and responsibility have been identified as crucial elements required to enable students to speak up (Ahern \& McDonald 2002).

\section{Contextual antecedents}

Organizational structure, culture and silence

Nurses work in organizations that aim for optimal relationships and improved relationships across disciplines and professional levels (Garon 2012, Johnson \& Kimsey 2012). In spite of this, open communication has been identified as a problem internationally (Mannion \& Davies 2015). Contemporary approaches to patient safety management emphasize the need for managers to focus on the learning that comes from making mistakes. Frontline providers are encouraged and should be willing to report errors, incidents and near misses, including their own and others (Barnsteiner \& Disch 2012). However, organizational silence is evident amongst the health workforce. In a survey of staff about whistleblowing $24 \%$ of respondents reported they had been warned off reporting and $45 \%$ reported their employer took no responsive action (NHS Staff Survey 2012). In this environment, students and nurses may feel disclosing or speaking out will not be taken seriously, or acted on and that they may be at personal risk.

Organizational silence is an oppressive culture that is directed down from management to the unit level and relates to the perceived negative impact on the overall organization (Henriksen \& Dayton 2006). Research exploring patient safety in English pre-registration nursing degree curricula found that student' perceptions are that the organizational culture of the practice setting was defensive, concealing and blaming (Attree et al. 2008). Open communication in the workplace is considered to facilitate speaking up. However, students have recognized a workplace culture that is not impartial and fair, impacting their sense of safety to speak up about patient safety (Barnsteiner \& Disch 2012). A just culture enables students to be confident and not concerned that there is a risk of punishment and burden. Students are mindful of their safety responsibilities, yet they have articulated a fear of potential professional consequences of speaking up, including being negatively labelled (Ion et al. 2015).

\section{Supervision and support}

There are challenges relating to supervision and support including students sense of belonging or being part of the team while on clinical placement (Levett-Jones \& Lathlean 2009). Students expressed, at times, they feel they are exploited or ignored and experience difficulty with workplace relationships. This results in a sense of needing to 
back down on issues no matter if right or wrong for the sake of maintaining workplace relationships (Suresh et al. 2012). Students on placement have identified a feeling of abandonment, resulting in not being enabled to engage in activities unless their supervisor is present. Furthermore, when students engaged by notifying their concerns, they reported the outcome was demeaning, which included name-calling and offensive language (Melincavage 2011). Finally, students identified education providers' reprimand students who disclose errors (Dolansky et al. 2013). Consequently, fear of reprimand may prevent engagement in learning which may lead to more errors (Reader 2015) and not support students' courage to speak up about a clinical or moral wrong.

\section{Consequence of speaking up}

Possible consequences of speaking up while on clinical placement reported by students included negative impact such as distress, being ostracised, reprimanded or even failing clinical placement (Bellefontaine 2009, Levett-Jones \& Lathlean 2009, Ion et al. 2015). Moral distress occurs when nurses find themselves in situations where they feel unable to do the right thing. Advocating unsuccessfully for patients has been associated with lack of professional respect and professional roles, which lead to moral distress (Gallagher 2011). Students felt at times they had no choice but to report incidents they thought put patients at risk of harm, some things they observed were morally distressing and in some instances remained with them for some time (Ion et al. 2015).

Students identified a fear of consequences related to speaking up, such as an impact on their grade including workplace staff not willing to complete student's clinical assessments or placement reports (Bellefontaine 2009, Ion et al. 2015). The negative consequence was considered to be so great that instead of speaking up, some students considered withdrawing or even taking time out from their nursing program (Myall et al. 2008). Registered Nurses identified speaking up at a unit level rather than at an organizational level or external to the health facility is considered less risky (Garon 2012). However, students felt a potential for reprimand by either or both the ward and the university (Bellefontaine 2009). Students who engaged in questioning behaviours have been identified as disruptive, 'rocking the boat' by speaking up which can lead to ostracism (Levett-Jones \& Lathlean 2009). Indeed, people who speak up have been viewed as troublemakers in the workplace with some health professionals being treated differently by their peers after reporting errors or misconduct. Some have even held a fear for their personal safety
(Jackson et al. 2010). However, the consequence of speaking up is not always negative. Strengthened interprofessional collaboration and professional respect (Kolbe et al. 2012) are positive consequences and students have also expressed a sense of pride and satisfaction in their actions when they have spoken up (Ion et al. 2015).

\section{Perceived effectiveness}

The desired effectiveness of voicing concerns is to immediately stop actions that may result in patient harm (Andrew \& Mansour 2014). However, students' have expressed a sense of ambiguity when at times they found it was pointless, believing that even when the unsafe practice was known and was a common occurrence knowing others had previously spoken up (Ion et al. 2015). The degree to which students are being heard is difficult to assess. Receiving feedback is the clearest measure; however, at times the response was silence, therefore, making it difficult for students to measure the perceived effectiveness of their actions (Garon 2012).

\section{Discussion}

This concept analysis of nursing students speaking up revealed the individual and contextual factors influencing students speaking up in the workplace. Contextual factors include organization safety culture, supervision and support, professional role and responsibilities. These contextual elements influence the student responses; however, it is also necessary to identify individual factors that influence actions. Nursing students' moral and ethical positions, safety education, confidence and willingness to speak up are also key influencing factors. Speaking up as an act of advocacy, for student nurses is characterised by how voice is used and influenced by individual and contextual factors such as confidence, agency and organizational culture (Garon 2012, Morrison 2011). Student nurses are most likely to speak up when they are concerned for the patient and when perceive they environment to be supportive (Barnsteiner \& Disch 2012, Mansbach et al. 2013).

Speaking up confidence has been found to increase after students engage in education on communication and challenging conflict (Sayer et al. 2012, Kent et al. 2015). However, students identified some difficulty when speaking up to persons with authority. Furthermore, they were more willing to report errors or misconduct at an internal level rather than at an external or organizational level (Mansbach et al. 2013, 2014). Moral distress experienced by the student is challenged by their moral courage and simultaneously influenced by the organizational culture (Gallagher 
2011). The perception of being heard when speaking up is an influencing factor that can be considered risky and challenging to RNs (Garon 2012, Law \& Chan 2015). And as such, nursing students may have similar concerns, though research to date does not assimilate elements such as organizational divisions and roles and responsibilities. Students are exposed to the same precursors that influence RNs speaking up behaviours, that is, the fear of negative retribution and consequences remain, though the consequence may be viewed differently (Andrew \& Mansour 2014).

Nursing students need to be willing to engage in using effective voice to deliver messages and raise concerns. It is the students' poor sense of agency in the workplace that challenges their willingness, which may result in active silence. Before formally disclosing the issue or concern, nurses sometimes engage in conversation such as the use of humour or sarcasm and seeking a second opinion to signal there is concern or discontent (Mannion \& Davies 2015). They also use 'off the record' conversations between employees across various professional levels to express concerns (Kelly \& Jones 2013). However, students' confidence leads them to be less likely to engage in such conversations (Levett-Jones \& Lathlean 2009).

Identified areas where health professionals can speak up include; observing short cuts in practice, witnessing errors, when clinical support or teamwork is lacking, incompetence, disrespectful or disruptive behaviour and finally poor or micromanagement (Moss \& Maxfield 2007, Henneman et al. 2010, Kolbe et al. 2012, Schwappach \& Gehring 2014). The relationship between the characteristics of nursing students speaking up needs to be explored focusing on replicating the real workplace issues and challenges. Understanding the students' position in the workplace, focusing on aspects relating to speaking up about errors, aims to provide knowledge and information that will improve patient safety. Students' described the workplace culture as one that is blaming and punishing (Ion et al. 2015), unjust and unfair, therefore, giving a reason why they do not feel that is safe to speak up (Law \& Chan 2015). An impartial culture or just culture would enable students to speak up when they have concerns about safety (Barnsteiner \& Disch 2012). A just culture is one that has no fear of reprisal and liability and an atmosphere of confidence (Barnsteiner \& Disch 2012). Exposure to situations that challenge students' professional and moral understandings helps them develop skill, voice, agency and courage. Gallagher (2011) suggests that courage is developed by getting into the habit of acting courageously as a reflective activity. Furthermore, courage requires selfscrutiny and learning from the feedback and role modelling of others. Students desire an applied approach to speaking up education, it is suggested that scenario-based learning and a reflective approach would be beneficial in developing skills helping them deal with such situations (Ion et al.'s 2015). This is where simulated situated environments could have a role in providing a safe learning context.

\section{Limitations}

Investigation into nursing students is limited due to the small number of studies that focus on students. Student experience in the clinical setting literature was used to concentrate on the organizational context. However, it was limited to literature focusing on students speaking up in the workplace context. Also, the inclusion of only English language articles limits the content from research conducted in other languages, therefore their content and perspectives.

\section{Conclusion}

Keeping patients safe from harm is a central goal of nursing care. Exploration of the ways nurses' practice to achieve patient safety is critical if student nurses are to become safe practitioners. Speaking up is a complex social practice that requires negotiation in complicated cultural and organizational circumstances that is challenging for students. Nursing students' transient position and engagement in the workplace brings different perspectives to safety culture, workplace structure and professional roles and responsibilities because they are both learners and visitors to a clinical organization. Their role and position of subservience influence their self-perception of the value of their contribution; and, their confidence to speak up. Organizational and individual antecedents including the students' sense of agency and their role as a patient advocate leads them to either speak up or to remain silent. Characteristics of voice, silence and being heard are key aspects for students when speaking up in the workplace. Future research is needed to investigate strategies to enhance nursing students speaking up in the workplace. The ultimate goal of such research is to enable nursing students to speak up effectively to prevent patient harm and improve patient safety.

\section{Funding}

This research received no specific grant from any funding agency in the public, commercial or not-for-profit sectors.

\section{Conflict of interest}

No conflict of interest has been declared by the authors. 


\section{Author contributions}

All authors have agreed on the final version and meet at least one of the following criteria [recommended by the ICMJE (http://www.icmje.org/recommendations/)]:

- substantial contributions to conception and design, acquisition of data, or analysis and interpretation of data;

- drafting the article or revising it critically for important intellectual content.

\section{References}

Ahern K. \& McDonald S. (2002) The beliefs of nurses who were involved in a whistleblowing event. Journal of Advanced Nursing 38, 303-309.

American Nurses Association (2015) Code of Ethics for Nurses With Interpretive Statements. Silver Spring. Retrieved from http://www.nursesbooks.org/Main-Menu/Ethics/Code-of-Ethics.as px on 17 August 2015.

Andrew S. \& Mansour M. (2014) Safeguarding in medication administration: understanding pre-registration nursing students' survey response to patient safety and peer reporting issues. Journal of Nursing Management 22, 311-321.

Attree M. (2007) Factors influencing nurses' decisions to raise concerns about care quality. Journal of Nursing Management 15, 392-402.

Attree M., Cooke H. \& Wakfield A. (2008) Patient safety in an English pre-registration nursing curriculum. Nurse Education in Practice 8, 239-248.

Baldwin M.A. (2003) Patient advocacy: a concept analysis. Nursing Standard 17(21), 33-39.

Barnsteiner J. \& Disch J. (2012) A just culture for nurses and nursing students. The Nursing Clinics of North America 47, 407-416.

Bellefontaine N. (2009) Exploring whether student nurses report poor practice they have witnessed on placements. Nursing Times 105(35), 28-31.

Curtin L.L. (1979) The nurse as advocate: a philosophical foundation for nursing. Advances in Nursing Science 1, 1-10.

Department of Health/Patient Safety (2012) The Never Events Policy Framework: An Update to the Never Events Policy. National Health Service, London. Retrieved from http:// www.idsc-uk.co.uk/docs-2012/never-events-policy-framework-up date-to-policy.pdf on 16 July 2015.

Dendle C., Paul A., Scott C., Gillespie E., Kostanas D. \& Stuart R.L. (2013) Why is it so hard for doctors to speak up when they see an error occurring? Healthcare Infection 18, 72-75.

Dolansky M.A., Druschel K., Helba M. \& Courtney K. (2013) Nursing student medication errors: a case study using root cause analysis. Journal of Professional Nursing 29(2), 102-108.

Firtko A. \& Jackson D. (2005) Do the ends justify the means? Nursing and the dilemma of whistle-blowing. Australian Journal of Advanced Nursing 23, 51-56.

Fowler D. (1989) Social Advocacy. Heart and Lung 18, 97-99.

Francis R. (2013) Report of the Mid Staffordshire NHS Foundation Trust Public Inquiry. Retrieved from http://www.midstffpublicin quiry.com/sites/default/files/report/Volume\%202.pdf on 16 July 2015.
Gadow S. (1980) Existential Advocacy; philosophical foundation of nursing. In Nursing, Images and Ideals (Spicker S. \& Gadow S., eds), Springer Publications, New York, pp. 387-398.

Gallagher A. (2011) Moral Distress and Moral Courage in Everyday Nursing Practice. OJIN: The Online Journal of Issues in Nursing 16(2).

Garling P. (2008) Final Report of the Special Commission of Inquiry: Final report of the Special Commission of Inquiry: Acute Care Services in NSW Public Hospitals, volume 2. NSW Department of Premier and Cabinet. Retrieved from http:// www.dpc.nsw.gov.au/_data/assets/pdf_file/0003/34194/Overview _-_Special_Commission_Of_Inquiry_Into_Acute_Care_Services_In _New_South_Wales_Public_Hospitals.pdf on 16 July 2015.

Garon M. (2012) Speaking up, being heard: registered nurses' perceptions of workplace communication. Journal of Nursing Management 20, 361-371.

Hendricks J.M. \& Cope V.C. (2013) Generational diversity: what nurse managers need to know. Journal of Advanced Nursing 69, $717-725$.

Henneman E.A., Roche J.P., Fisher D.L., Cunningham H., Reilly C.A., Nathanson B.H. \& Henneman P.L. (2010) Error identification and recovery by student nurses using human patient simulation: opportunity to improve patient safety. Applied Nursing Research 23, 11-21.

Henriksen K. \& Dayton E. (2006) Organizational silence and hidden threats to patient safety. Health Services Research 41, 1539-1554.

Ion R., Smith K., Nimmo S., Rice A.M. \& McMillan L. (2015) Factors influencing student nurse decisions to report poor practice witnessed while on placement. Nurse Education Today 35, 900-905.

Jackson D., Peters K., Andrew S., Edenborough M., Halcomb E., Luck L., Salamonson Y., Weaver R. \& Wilkes L. (2010) Trial and retribution: a qualitative study of whistleblowing and workplace relationships in nursing. Contemporary Nurse 36, 34-44.

Jackson D., Hutchinson M., Everett B., Mannix J., Peters K., Weaver R. \& Salamonson Y. (2011) Struggling for legitimacy: nursing students' stories of organisational aggression, resilience and resistance. Nursing Inquiry 18, 102-110.

Jackson D., Hickman L.D., Hutchinson M., Andrew S., Smith J., Potgieter I. \& Peters K. (2014) Whistleblowing: an integrative literature review of data-based studies involving nurses. Contemporary Nurse, 48 240-252.

Jansson B.S. (2011) Improving Healthcare through Advocacy: A Guide for the Health and Helping Professions. John Wiley \& Sons, New Jersey, USA.

Johnson H.L. \& Kimsey D. (2012) Patient safety: break the silence. AORN Journal 95, 591-601.

Kelly D. \& Jones A. (2013) When care is needed: the role of whisteblowing in promoting best standards from an individual and organizational perspective. Quality Ageing Older Adults 14, 180-191.

Kent L., Anderson G., Ciocca R., Shanks L. \& Enlow M. (2015) Effects of a senior practicum course on nursing students' confidence in speaking up for patient safety. Journal of Nursing Education, 54, S12-S15.

Kohn L.T. (2000) To Err Is Human: Building A Safer Health System. National Academy Press, Washington, DC. Retrieved 
from http://books.nap.edu/openbook.php?isbn $=0309068371$ on 16 July 2015.

Kolbe M., Burtscher M.J., Wacker J., Grande B., Spahn D.R. \& Grote G. (2012) Speaking up is related to better team performance in simulated anesthesia inductions: an observational study. Anesthesia and Analgesia 115, 1099-1108.

Konke M. (1982) Advocacy, Risks and Reality. CV Mosby Co, St Louis, MO.

Law B.Y. \& Chan E.A. (2015) The experience of learning to speak up: a narrative inquiry on newly graduated registered nurses. Journal of Clinical Nursing 24, 1837-1848.

Levett-Jones T. \& Bourgeois S. (2014) The Clinical Placement: An Essential Guide for Nursing Students. Elsevier, Sydney, Australia.

Levett-Jones T. \& Lathlean J. (2008) Belongingness: A perquisite for nursing students' clinical learning. Nurse Education in Practice 8, 103-111.

Levett-Jones T. \& Lathlean J. (2009) 'Don't rock the boat': nursing students' experiences of conformity and compliance. Nurse Education Today 29, 342-349.

Lyndon A., Sexton J.B., Simpson K.R., Rosenstein A., Lee K.A. \& Wachter R.M. (2012) Predictors of likelihood of speaking up about safety concerns in labour and delivery. British Medical Journal Quality Safety 21, 791-799.

Mannion R. \& Davies H.T. (2015) Cultures of silence and cultures of voice: the role of whistleblowing in healthcare organisations. International Journal of Health Policy Management 4(8), 503-505.

Mansbach A., Ziedenberg H. \& Bachner Y.G. (2013) Nursing students' willingness to blow the whistle. Nurse Education Today 33, 69-72.

Mansbach A., Kushnir T., Ziedenberg H. \& Bachner Y.G. (2014) Reporting misconduct of a coworker to protect a patient: a comparison between experienced nurses and nursing students. The Scientific World Journal 2014, 41392.

Mariani B., Cantrell M.A., Meakim C. \& Jenkinson A. (2015) Improving students' safety practice behaviors through a simulation-based learning experience. Journal of Nursing Education 54, S35-S38.

Maxfield D., Grenny J., McMillan R., Patterson K. \& Switzler A. (2005) Silence Kills. The Seven Crucial Conversations for Healthcare. American Association of Critical Care Nurses; Association of perioperative Registered Nurses; Vital Smarts, Aliso Viejo (CA).

Maxfield D., Grenny J., Lavandero R. \& Groah L. (2011) The silent treatment: why safety tools and checklist aren't enough to save lives. Patient Safety and Quality Healthcare. Retrieved from http://www.aacn.org/wd/hwe/docs/the-silent-treatment.pdf on 25 July 2015.

Melincavage S.M. (2011) Student nurses' experiences of anxiety in the clinical setting. Nurse Education Today 31, 785-789.

Morrison E.W. (2011) Employee voice behavior: integration and directions for future research. The Academy of Management Annals 5, 373-412.

Moss E. \& Maxfield D. (2007) Silence kills: a case manager's guide to communication breakdowns in healthcare part 1 of 3 . Professional Case Management 12, 52-54.

Myall M., Levett-Jones T. \& Lathlean J. (2008) Mentorship in contemporary practice: the experiences of nursing students and practice mentors. Journal of Clinical Nursing 17, 1834-1842.
NHS Staff Survey (2012) Department of Health, London. Retrieved from https://www.gov.uk/government/uploads/system/uploads/ attachment_data/file/215455/dh_129656.pdf on 11 October 2015.

Nursing Council of New Zealand (2012) Code of Conduct. Retrieved from http://www.nursingcouncil.org.nz/Nurses/Codeof-Conduct on 11 October 2015.

Nursing and Midwifery Board of Australia (2008a) Code of Ethics for Nurses in Australia. Nursing and Midwifery Board of Australia, Melbourne, Australia. Retrieved from www.nursingmidwiferyboard.gov.au on 11 October 2015.

Nursing and Midwifery Board of Australia (2008b) Code of Professional Conduct. Nursing and Midwifery Board of Australia, Melbourne, Australia. Retrieved from www.nursingmidwiferyboard.gov.au on 11 October 2015.

Okuyama A., Wagner C. \& Bijnen B. (2014) Speaking up for patient safety by hospital-based health care professionals: a literature review. BMC Health Services Research 14, 1-17.

Peters K., Luck L., Hutchinson M., Wilkes L., Andrew S. \& Jackson D. (2011) The emotional sequelae of whistleblowing: findings from a qualitative study. Journal of Clinical Nursing 20, 2907-2914.

Premeaux S.F. \& Bedeian A.G. (2003) Breaking the silence: the moderating effects of self-monitoring in predicting speaking up in the workplace. Journal of Management Studies 40, 15371562. Retrieved from http://onlinelibrary.wiley.com/doi/10.1111/ 1467-6486.00390/pdf on 12 August 2015.

Rainer J. (2015) Speaking up factors and issues in nurses advocating for patients when patients are in jeopardy. Journal of Nursing Care Quality 30, 53-62.

Reader R.L. (2015) Students' experiences in associate degree nursing programs: a qualitative study looking at moral distress. Teaching and Learning in Nursing 10, 118-123.

Reason J. (2000) Human error: models and management. BMJ 320 (7237), 768-770. Retrieved from http://www.ncbi.nlm.nih.gov/ pmc/articles/PMC1117770/ on 12 August 2015.

Sayre M., McNeese-Smith D., Phillips L. \& Leach L.S. (2012) A strategy to improve nurses speaking up and collaborating for patient safety. The Journal of Nursing Administration 42, 458-460.

Schwappach D.L.B. \& Gehring K. (2014) Silence that can be dangerous: a vignette study to assess healthcare professionals' likelihood of speaking up about safety concerns. PLOS ONE 9, 1-8.

Suresh P., Matthews A. \& Coyne I. (2012) Stress and stressors in the clinical environment: a comparative study of fourth-year student nurses and newly qualified general nurses in Ireland. Journal of Clinical Nursing 22, 770-779.

Tella S., Smith N., Partanen P. \& Turunen H. (2015) Learning patient safety in academic settings: a comparative study of Finnish and British nursing students' perceptions. World Views on Evidence-Based Nursing 12, 154-164.

Walker L.O. \& Avant K.C. (2005) Concept analysis. Strategies for theory construction in nursing 3, 37-54.

Walker L.O. \& Avant K.C. (2010) Strategies for Theory Construction in Nursing, 5th edn. Pearson Prentice Hall, Upper Saddle River, NJ.

Walker S., Dwyer T., Broadbent M., Moxham L., Sander T. \& Edwards K. (2014) Constructing a nursing identity within the clinical environment: the student nurse experience. Contemporary Nurse 49, 103-112. 
A. Fagan et al.

WHO (2009) World Health Organisation Patient Safety Curriculum Guide. Retrieved from http://www.who.int/patient safety/education/curriculum/en/ on 25 July 2015.

World Health Organization (2015) 10 Facts on Patient Safety. Retrieved from http://www.who.int/features/factfiles/patient_ safety/patient_safety_facts/en/index $7 . h t m l$ on 18 September 2015.

Xu Y., Davidhizar R. \& Joyce N.G. (2005) What if your nursing student is from an Asian culture? Journal of Cultural Diversity $12,5-11$.

The Journal of Advanced Nursing (JAN) is an international, peer-reviewed, scientific journal. JAN contributes to the advancement of evidence-based nursing, midwifery and health care by disseminating high quality research and scholarship of contemporary relevance and with potential to advance knowledge for practice, education, management or policy. JAN publishes research reviews, original research reports and methodological and theoretical papers.

For further information, please visit JAN on the Wiley Online Library website: www.wileyonlinelibrary.com/journal/jan

$\underline{\text { Reasons to publish your work in JAN: }}$

- High-impact forum: the world's most cited nursing journal, with an Impact Factor of 1.741 - ranked 8/109 in the 2014 ISI Journal Citation Reports (C) (Nursing (Social Science)).

- Most read nursing journal in the world: over 3 million articles downloaded online per year and accessible in over 10,000 libraries worldwide (including over 3,500 in developing countries with free or low cost access).

- Fast and easy online submission: online submission at http://mc.manuscriptcentral.com/jan.

- Positive publishing experience: rapid double-blind peer review with constructive feedback.

- Rapid online publication in five weeks: average time from final manuscript arriving in production to online publication.

- Online Open: the option to pay to make your article freely and openly accessible to non-subscribers upon publication on Wiley Online Library, as well as the option to deposit the article in your own or your funding agency's preferred archive (e.g. PubMed). 